\title{
Pueblos arroceros en la cuenca del Cebollatí: asentamientos surgidos a partir de la instalación del cultivo de arroz
}

\author{
SELECCIÓN VIII SEMINARIO INTERNACIONAL DE INVESTIGACIÓN EN URBANISMO
}

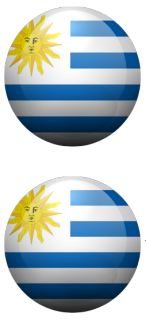

\section{Susana Martinez Benia}

Maestría en Ordenamiento Territorial y Desarrollo Sostenible (en curso), Universidad de la República, Facultad de Arquitectura. Montevideo [Montevideo] Uruguay. smartinezbenia@gmail.com

\section{María Mercedes Medina Acosta}

Arquitecta, Magister en Ordenamiento Territorial y Desarrollo Urbano [UdelaR], Doctora en Urbanismo [Universidad Politécnica de Cataluña]. Profesora Titular de la Facultad de Arquitectura, Diseño y Urbanismo, de la Universidad de la República. Montevideo [Montevideo] Uruguay. mmedina.uy@gmail.com

\section{Resumen}

A partir de la segunda mitad del SXIX, la organización productiva de la explotación de arroz, en la cuenca baja del Cebollatí, dio origen a pueblos arroceros que se han desarrollado en constelaciones convergiendo en nodos calificados de segundo y tercer nivel, en un paisaje particular y atractivo, donde los aspectos culturales y naturales se combinan. Varios usos productivos han estado asociados a la estructuración del territorio, en donde la formulación de asentamientos concebidos para la producción y organizados en forma semiautónoma son parte sustantiva. El territorio es un proceso y un producto de prácticas individuales y grupales, en el que conviven un patrimonio arqueológico - cerritos de indios-, que apelan a las raíces y a los primeros habitantes de nuestro territorio, un paisaje natural de llanuras, esteros, lagunas y montes naturales, y el paisaje cultural generado por el cultivo e industrialización del arroz. Este trabajo se aborda desde la perspectiva territorial: soporte físico más construcción histórica.

\section{Palabras clave}

Territorio. Paisajes culturales. Recursos patrimoniales. Desarrollo local.

\section{Rice towns in the Cebollatí basin: settlements arising from the installation of paddy cultivation}

\begin{abstract}
From the second half of SXIX, the productive organization of the exploitation of rice, in the lower basin of Cebollatí, led to rice villages that have developed into constellations converging qualified second and third level in a particular landscape nodes and attractive, where cultural and natural aspects are combined. Several productive uses have been associated with the structuring of the territory, where settlements formulation designed for production and are organized as semi-autonomous substantive part. The territory is a process and a product of individual and group practices, in which live arqueológico -Cerritos assets of Indians-, who appeal to the roots and the first inhabitants of our territory, a natural landscape of plains, marshes, lagoons and natural forests, and cultural landscape generated by rice cultivation and industrialization. This work is approached from the territorial perspective: most historic building hardware.
\end{abstract}

\section{Keywords}

Territory. Cultural landscape. Patrimonial resourses. Local development. 


\section{Introducción}

Como en la mayoría de los lugares del mundo, la estructura de los asentamientos de agricultura, se relacionan con el entorno y la disponibilidad de recursos. En la cuenca de la laguna Merin, al comenzar el cultivo arroz, en la segunda mitad del siglo XX, se desencadenaron una serie de procesos que implicaron importantes transformaciones en el territorio.

Desde la perspectiva territorial, en nuestro medio, los poblados arroceros han recibido muy poca atención. En este encuentro con el tema, se abre la idea de que estamos ante un fenómeno territorialurbano de relevancia en la ocupación del espacio y en la consolidación de un área productiva y natural. Se procura interpretar y comprender la lógica territorial descubriendo las huellas que marcó la historia, considerando el territorio como objeto construido. Para ello nos aproximamos en tres niveles: el histórico, el de los procesos ocurridos, las transformaciones actuales y el contexto de la interpretación.

La investigación se centra en el relevamiento estructural, formas de organización, ocupación y actividades del territorio, reconstrucción de hilos argumentales para narrar la historia del lugar y ofrecer oportunidades basándose en la identidad del territorio para futuros proyectos, en síntesis poner los recursos patrimoniales al servicio del desarrollo local. Se realiza trabajo de campo en más de 30 pueblos. Se trabajacon diferentes fuentes documentales, entrevistas a informantes claves, consulta de archivos, cartografía, datos censales, fotos aéreas, satelitales, normativa vigente y bibliografía.

Este trabajo explica la arquitectura, el urbanismo y el paisaje de los pueblos del arroz desde la historia y los intereses políticos, sociales y económicos que hicieron posible el fenómeno.

\subsection{Ubicación}

La zona objeto de la investigación está ubicada en cuenca de la Laguna Merin, una cuenca binacional que comparten Uruguay y Brasil.

En la porción uruguaya, dentro del área Reserva de Biósfera de Bañados del Este, se realiza el recorte territorial, de $3700 \mathrm{~km}^{2}$ : al Norte el río Tacuarí, al este la Laguna Merim, el Arroyo Los Corrales y el Río Cebollatí al sur y al oeste el eje Ruta Nacional № 8 -18, de enlace con Brasil que articula las distintas localidades urbanas y Montevideo con el Estado de Río Grande del Sur en Brasil ${ }^{1}$.

El arroz es una de las actividades agropecuarias de mayor dinamismo en el Uruguay, al punto que se ha constituido en el tercer rubro de exportación, sin duda por el buen relacionamiento que ha existido entre el sector primario y el sector industrial, donde la cadena agroindustrial ha logrado un alto grado de integración ${ }^{2}$.

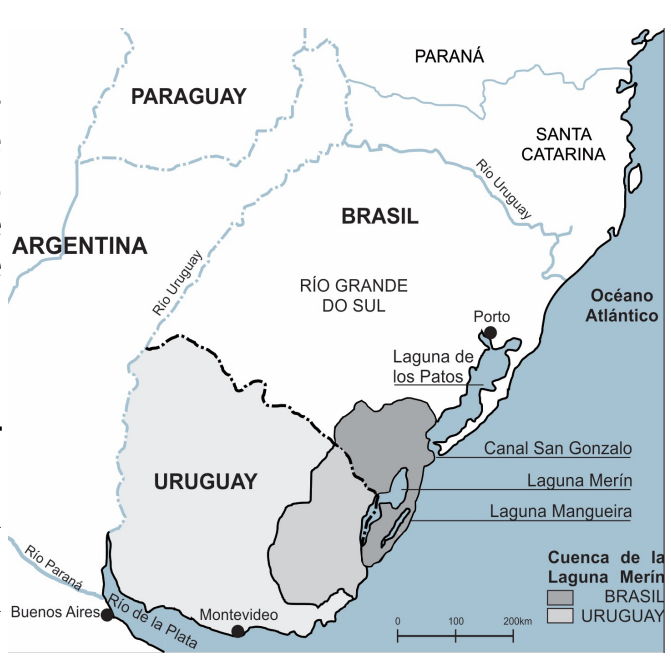

Figura 1. Ubicación.

\section{Objetivos}

La investigación se centra en la puesta en valor y la sistematización de la estructura territorial producto del cultivo de arroz.

\footnotetext{
${ }^{1}$ Reconocida e integrada en el año 1976 a la red mundial del programa El Hombre y La Biósfera (MAB) de la Unesco. En el año 1998/99 se realiza el Plan Director de Probides, donde se delimita el territorio y se elaboran propuestas y se establecen mecanismos que permiten consideraciones básicas para el manejo de las reservas de biósfera.

${ }^{2}$ El arroz ocupa un promedio de una persona cada 33 hectáreas de cultivo. (Datos suministrados por el productor Freddy Lago, ex directivo de la Asociación de Cultivadores de Arroz).
} 

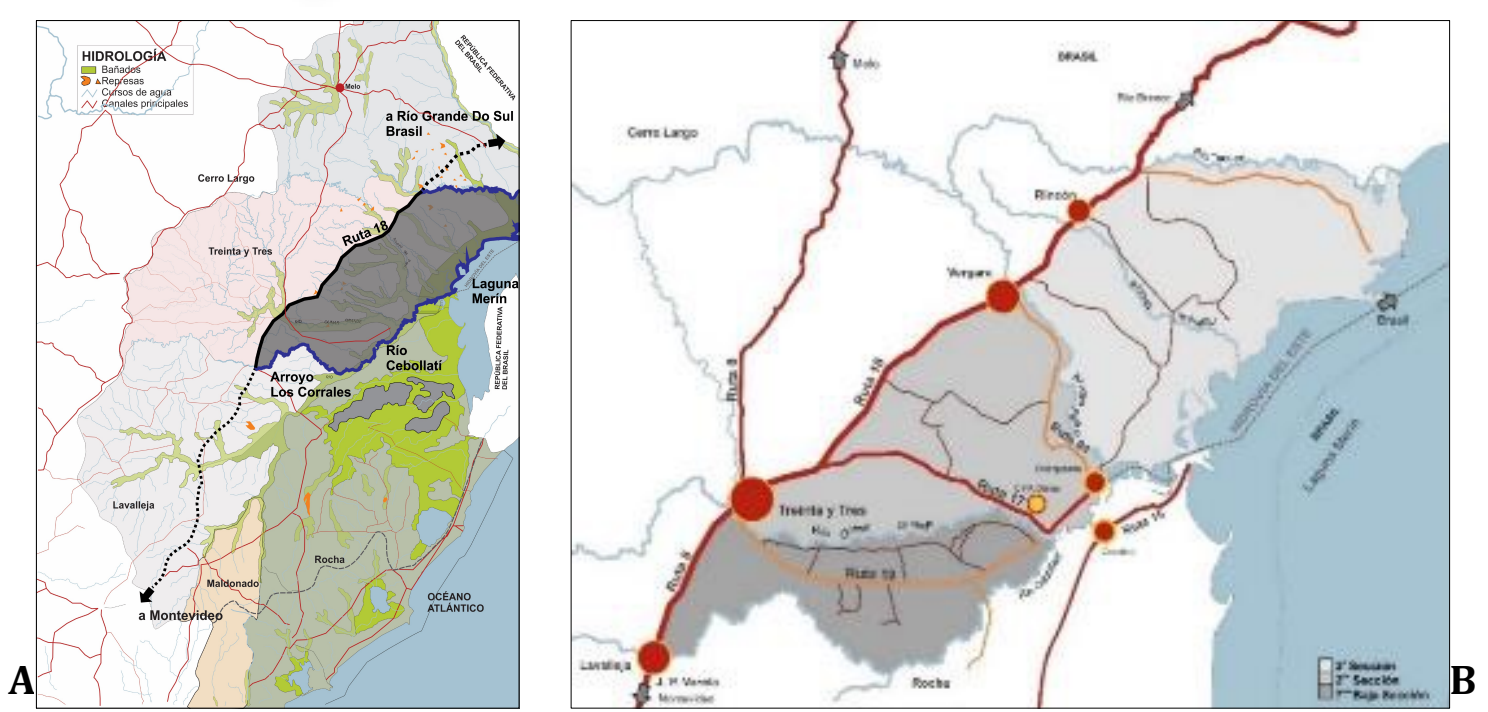

Figura 2. Plano A: Zona de actuación en el contexto regional. Fuente: Plan Director de Probides (1998). Plano B: Limites de la zona de estudio. Fuente: Elaboración propia.

La región, no escapa a la tendencia mundial del éxodo campo-ciudad, que provoca el despoblamiento del área rural. En el territorio se generan una trama de relaciones, de conexiones, articuladas en un sistema de actividades que producen configuraciones territoriales. El propósito es avanzar en el conocimiento de lo local, reconocer su historia y ponerla en valor. Para esto es necesario traducir los patrones de comportamiento promoviendo el rescate de la identidad histórico-cultural como oportunidad para desencadenar procesos de desarrollo identificando las trazas, huellas de estos patrones en el territorio para incorporarlos en los procesos planificadores. Se busca utilizar los recursos culturales para mejorar la calidad de vida de los ambientes rurales, donde se localizan los puebles del arroz y vincular el patrimonio cultural y las redes de espacios naturales.

Se realiza una revisión y revaloración del conocimiento empírico y teórico sobre el tema, para poner en valor los recursos patrimoniales (productivos, industriales, naturales y culturales) y promover el desarrollo local. Se trata de construir un futuro mejor para sus habitantes respetando la identidad del territorio.

Se ubica también ahí, un patrimonio poco conocido y amenazado, un importante patrimonio arqueológico (cerritos de indios) y paleontológico, que apela a las raíces y a los primeros habitantes de nuestro territorio y un patrimonio natural con alto valor ambiental, a la orilla de la Laguna Merin, una de las mayores reservas de agua dulce del planeta. La puesta en valor de los recursos naturales y culturales, como parte de un mismo concepto: patrimonio, permitiría reforzar la identidad local $\mathrm{y}$ fortalecer las comunidades que lo habitan.

Identificar las potencialidades del territorio, generando sinergias entre el mosaico de situaciones diferentes, comenzar la construcción de un proyecto territorial que active el desarrollo local considerando un turismo cultural donde los visitantes conozcan los paisajes cotidianos y participen de cómo vive y produce la gente.

El objetivo es activar los recursos culturales, para que se pongan al servicio del desarrollo local. No se trata solamente de conservar sino de intervenir, teniendo en cuenta todos los recursos, para ponerlos en valor, vincular la historia con el planeamiento y anclarlo en el pasado para proyectarlo. El paisaje cultural es la huella del trabajo sobre el territorio, lo cual sugiere una conformación a través de acciones concretas sin un proceso de finalización, un palimsesto, sobre el que se puede escribir y borrar lo escrito para reescribir.

\section{Hipótesis}

De acuerdo a los objetivos y al abordaje planteado con diferentes miradas: desde el ordenamiento territorial, desde el territorio y desde el turismo cultural, se plantean tres hipótesis de trabajo: 
- Los pueblos arroceros tienen valores latentes sobre los cuales sustentar un desarrollo basado en el turismo cultural.

- Un proyecto territorial, basado en el binomio naturaleza-cultura, donde el paisaje cultural del arroz y los pueblos arroceros sean protagonistas se constituye en una oportunidad para promover el desarrollo local.

- Existen en el territorio de la cuenca arrocera, actores con los cuales sustentar el desarrollo local basado en la puesta en valor de los recursos patrimoniales.

\subsection{Contexto histórico de fundación}

La crisis económica mundial, iniciada en 1929 en Estados Unidos, repercutió en Uruguay. En el período 1903-1930, el país, a través del reformismo del período batllista, consolida la democracia, la reforma social y el bienestar económico ${ }^{3}$. A partir de 1930, las restricciones en el mercado internacional, la baja en el precio de las exportaciones de materia prima y alimentos, generan aumento de desocupación y caída del ingreso. En esa situación, con una carga impositiva costosa, el estado es enjuiciado por la clase alta (estancieros y comerciantes), provocando en 1933, un golpe de estado dado por el presidente electo Gabriel Terra.

La baja de la producción agropecuaria (hay en ese momento menos ganado que treinta años antes en virtud de las escasas inversiones de los ganaderos y de la baja de los precios de la exportación), provoca que, Uruguay, al igual que otros países de América Latina desarrolle el sector industrial. El sector más beneficiado por el cambio es el de los propietarios rurales: se reducen los impuestos al agro, se suspende el pago de hipotecas sobre la propiedad rural, se mejora el pago a los productores ganaderos y se devalúa los tipos de cambio aplicable a las exportaciones entre otras medidas. En este contexto y en la búsqueda de nuevas actividades económicas para paliar la crisis, surgen las primeras poblaciones para albergar a los trabajadores del arroz.

\section{Sistema de ocupación}

Las actividades económicas provocaron cambios, se amplia el espacio ocupado y aparece una red de nuevos asentamientos. Estas transformaciones se relacionan con una serie de hechos. El proceso se inicia con una política que beneficia al sector agropecuario. La red de ferrocarriles se extiende desde Treinta y Tres, hasta la ciudad de Río Branco, elemento fundamental en la consolidación de algunos emprendimientos. Los nuevos asentamientos originan una nueva forma de habitar el campo, hasta entonces sola-mente ocupado por estancias y puestos de estancias, donde residen muy pocas personas. Los nuevos emprendimientos permiten a los habitantes de la zona contar con una fuente de trabajo y es hacia allí donde se desplazaban con su familia en pos de un trabajo seguro para mejorar su calidad de vida. J. M. Montaner (2008) define el concepto de sistema:

Un sistema es un conjunto de elementos heterogéneos (materiales o no), de distintas escalas, que están relacionados entre sí, con una organización interna que intenta estratégicamente adaptarse a la complejidad del contexto y que constituye un todo que no es explicable por la mera suma de sus partes. Cada parte del sistema está en función de otra; no existen elementos aislados. Dentro de los diversos sistemas que se pueden establecer, la arquitectura y el urbanismo son sistemas de tipo funcional, espacial, constructivo, formal y simbólico (Montaner, 2008, p.11).

De acuerdo con este concepto, podemos afirmar que la instalación de pueblos arroceros en la cuenca de la Laguna Merim, no son una simple suma, son parte de un sistema, que a su vez, está subordinado a sistema menor donde intervienen otros subsistemas. El sistema de ocupación se establece disperso, a modo de constelaciones ${ }^{4}$, relacionado con pueblos y ciudades existentes. La implantación se realiza a iniciativa y a cargo de las sociedades agrícola-ganaderas o propietarios de las tierras.

\footnotetext{
${ }^{3}$ José Batlle y Ordonez (1856-1929) domina este período, fue presidente del Uruguay en dos oportunidades (1903-1907), (1911-1915), "signo con sus ideas y a la vez expresó la sociedad de clases medias que estaba naciendo al amparo de la prosperidad económica y la facilidad del ascenso social” (Barrán, 1995).

${ }^{4}$ entendida como un sistema de ocupación del territorio constituido por unidades económicas que lo estructuran y le dan forma.
} 
Los primeros pueblos arroceros surgen en los años 30 por decisión de las empresas agropecuarias CIPA y Arrozal 33, que instituyen la siembra de arroz a gran escala en el departamento de Treinta y Tres. Se introducen nuevas tecnologías de producción que modifican el manejo del cultivo: obras de ingeniería, de regulación hídrica (represas y diques), de drenaje, canales para riego, levantes de agua, de infraestructura, caminería, puentes y alcantarillas, balsas en ríos y arroyos. Se pasa de una explotación ganadera extensiva a una explotación agrícola-ganadera. Un territorio despoblado con escasa accesibilidad pasa a ser soporte de una de las actividades productivas más importantes del país.

Estos nuevos asentamientos producen impacto geográfico, urbano-territorial, político, económico y social. La arquitectura y las instalaciones complementarias que posibilitaron el desarrollo de espacios para carga y descarga del grano, silos para acopio, depósitos y talleres de maquinaria, viviendas de los trabajadores rurales, escuela, policlínica, comedor, se constituyeron en concluyentes piezas del sistema. Fueron las empresas quienes edificaron las instalaciones y las viviendas para obreros, técnicos y propietarios. La cantidad de residencias fue variable, en relación directa con el área de cultivo. En estos pueblos, creados adonde antes solo había campos deshabitados, acudieron primero los trabajadores y luego, sus familias.

Cada pieza está relacionada entre sí, no hay ningún objeto aislado, existen relaciones entre los edificios y los valores del espacio común que ellos definen.

\subsection{Características de ocupación}

Los asentamientos en un principio son relativamente autónomos, cualidad que se fue perdiendo en el devenir de los años. Su implantación está asociada al manejo del agua y de las tierras para el cultivo. Se ocupa el territorio con un fin utilitario, funcional.

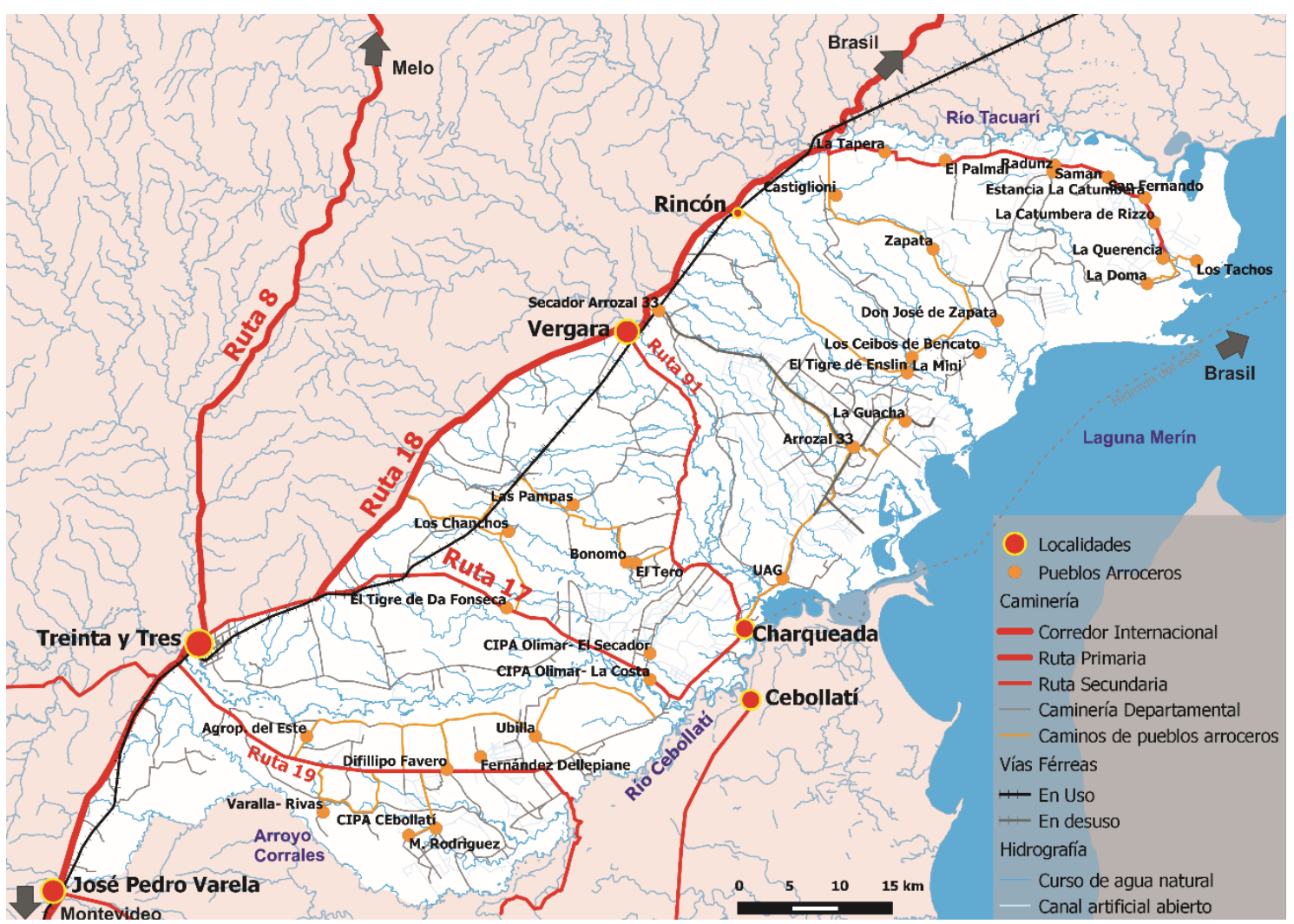

Figura 4. Sistema de pueblos arroceros (elaboración propia).

La planificación no sigue modelos teóricos, sino que es el resultado de la práctica de técnicos vinculados a los emprendimientos o de los propios productores agrícolas, sin proyecto urbano previo ni reglamentación.

Los pueblos se insertan en tierras propiedad de empresas agrícolas o productores particulares, en un territorio, cuya actividad principal y totalizadora es la agricultura. Con una ocupación del 
territorio dispersa, demuestran un sentido de permanencia y una dinámica mucho más limitada que en la ciudad.

Se establecen en sitios de fácil accesibilidad, al borde de caminos principales y equidistantes de las tierras de cultivo. Sobre esta formalización física y de producción se superponen la estructura de las unidades de producción.

Los pueblos se disponen en el territorio como constelaciones, en un sistema-red con dinámicas análogas y similares prácticas de ocupación y funcionamiento, relacionados con pueblos y ciudades cercanas. El grado de dispersión de la constelación depende de la superficie de cultivo de la empresa, sin embargo el mosaico en el que están inmersos los pueblos del arroz presentan regularidades resultado de su función y de las sensibilidades humanas.

En el caso de Arrozal 33, el desarrollo del ferrocarril entre la ciudad de Treinta y tres y Río Branco contribuye de manera decisiva al emprendimiento, ya que permite el transporte adecuado de la producción, en ese momento pensado en Montevideo, donde la empresa construye un molino junto al ferrocarril.

En la mayoría de los casos los asentamientos se disponen en el territorio, enmarcados por plantíos de eucaliptus como protección y resguardo de vientos predominantes y aporte de leña para el secado del grano.

\subsection{Morfología urbana}

La instalación del cultivo, produjo cambios en la fisonomía de los pueblos existentes. Aparecen nuevas funciones, relacionadas con el sector servicio e industrial que se ubican dentro y en las afueras del área urbana.

En los pueblos nuevos, con menor cantidad de actividades urbanas, se verificaba la existencia de una "cantina", o comercios, escuela, e instalaciones administrativas, de servicio e industriales sobre todo para el proceso de secado.

Las formas desarrolladas tienen que ver fundamentalmente con la ubicación de la vía de acceso. Si bien hay pueblos que se consolidan, hay otros que no prosperaron. El crecimiento o desaparición está relacionado con las posibilidades de producción y el avance de la tecnología.

Los principales objetivos para la creación de los pueblos del arroz están vinculados a facilitar al máximo la productividad y en menor medida a levantar referencias simbólicas que hacen presente en todo momento el orden con el cual funcionaba el conjunto.

La forma de los pueblos es el resultado de la interacción de tres variables: el soporte suelo (trazado de calles y de canales de riego), el uso del suelo y la edificación. Para analizar el patrón entonces, es necesario reconocer y aislar los elementos que lo conforman.

Se desarrollan por los menos cuatro formas urbanas de ocupación que dependen básicamente de la ubicación relativa al camino principal.

La forma de la trama urbana (Figura 5) o la disposición de los elementos estructurales de los pueblos son básicamente lineales, donde la vía de circulación es el eje vertebrador. Los edificios se construyen junto a la vía para minimizar los costos de acceso. En estas hileras, generalmente el único componente del asentamiento, se suelen generar espacios muy singulares. Por su lógica evidente, han surgido de forma espontánea en contextos muy diferentes a lo largo de la historia.

Sin embargo podemos considerar en algunos casos, una trama radial, apoyada en una red de caminos rurales que parten hacia las tierras de cultivo. Los elementos que forman el patrón son la vía, el parcelario asociado a ésta, los edificios y las centralidades.

En cuanto al uso del suelo, las actividades predominantes son: la primaria, agrícola y la secundaria, industria, aunque en menor grado se desarrollan actividades terciarias. Estas actividades, caracterizan 
la zona y requieren de una adecuación tanto de los espacios que alojan las actividades (parcelas y edificios) como de los canales de circulación.

El medio natural, limita el entramado viario que determina la estructura urbana, condiciona la disposición de la edificación y el sistema de movimientos. Los canales de regadío, principales y secundarios, estructuran el territorio al igual que las obras de infraestructura para reservar agua para riego conformando un sistema que organiza el paisaje.

T1

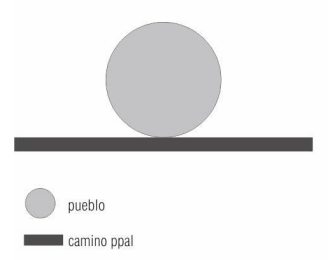

T1 Sobre el margen del camino principal

1. SAN FERNANDO
2. La Doma
3. Saman
4. EI Tigre Enslin
5. UAG
6. EI Tero
7. Bonomo
8. Los Chanchos
9. El Tigre Da Fonseca
10. Las Barracas
11. Varalla Rivas
12. Caraballo
13: CIPA Cebollati

T2

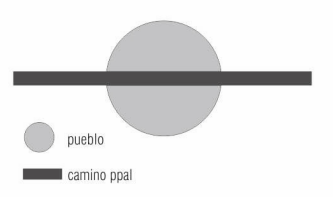

T2 A ambos lados del camino principal

1. ZAPATA

2. La Catumbera Rizzo

3. Los Tachos

4. La Tapera

5. La Querencia

6. La Mini

8. M. Rodriguez
T3

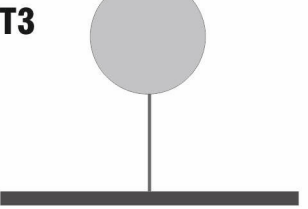

pueblo

camino ppal

T3 con un conector al camino principal

1. ARROZAL 33

2. La Guacha

3. Los Ceibos

4. Don José de Zapata

5. El Palmar

6. Castiglioni

7. Las Pampas
T4

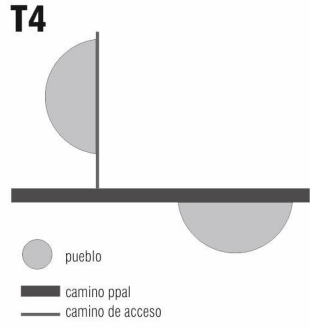

T4 desarrollado en dos

sectores

1_sobre camino principal

2 sobre conector c/cno. principal

1. CIPA OLIMAR

2. Radunz

Figura 5. Formas urbanas de ocupación (elaboración propia).

La forma y disposición de las construcciones en los pueblos, responde a los usos o actividades que albergan. La tipología edificatoria adoptada en estos lugares se relacionan con las actividades desarrolladas: viviendas unifamiliares aisladas y en algún caso pabellones habitacionales para solteros, alguna construcción para uso comercial, edificios de oficinas aislados, club social, escuela primaria, iglesia, policlínica, instalaciones industriales, silos para depósitos del cereal, edificios de talleres, almacenes, mantenimiento de maquinarias, etc.

\subsection{Funciones de los pueblos del arroz}

En la constitución de los pueblos para el desarrollo de la producción agrícola, las consideraciones morfológicas y metodológicas son similares, su creación se debe a una razón económica con una función dominante. En la mayoría de los casos se sigue el mismo patrón de asentamiento y ocupación del territorio.

Conviven en estos pueblos diversas actividades, (viviendas, con talleres, depósitos, servicios, instalaciones industriales, comercios) y es esa mixtura precisamente, la que aporta una morfología particular. La instalación de una fuente de trabajo en el área genera migración de población de las localidades vecinas, razón por la cual en un principio, se originan como entidades independientes.

Hoy, muchos pueblos arroceros, fundamentalmente los situados en la $7^{\circ}$ Baja, el territorio comprendido entre los Ríos Olimar, Cebollatí, Arroyo los Corrales y Ruta 8 se encuentran prácticamente deshabitados ya que los trabajadores viajan desde la ciudad de Treinta y Tres. Al mejorar la caminería, los habitantes se trasladan a las localidades cercanas y comienzan a desplazarse diariamente a los lugares de trabajo.

\subsection{Instalaciones y edificaciones del sistema}

Para entender el sistema de ocupación es necesario conocer los elementos que intervienen en el conjunto y comprender la conexión entre ellos. 


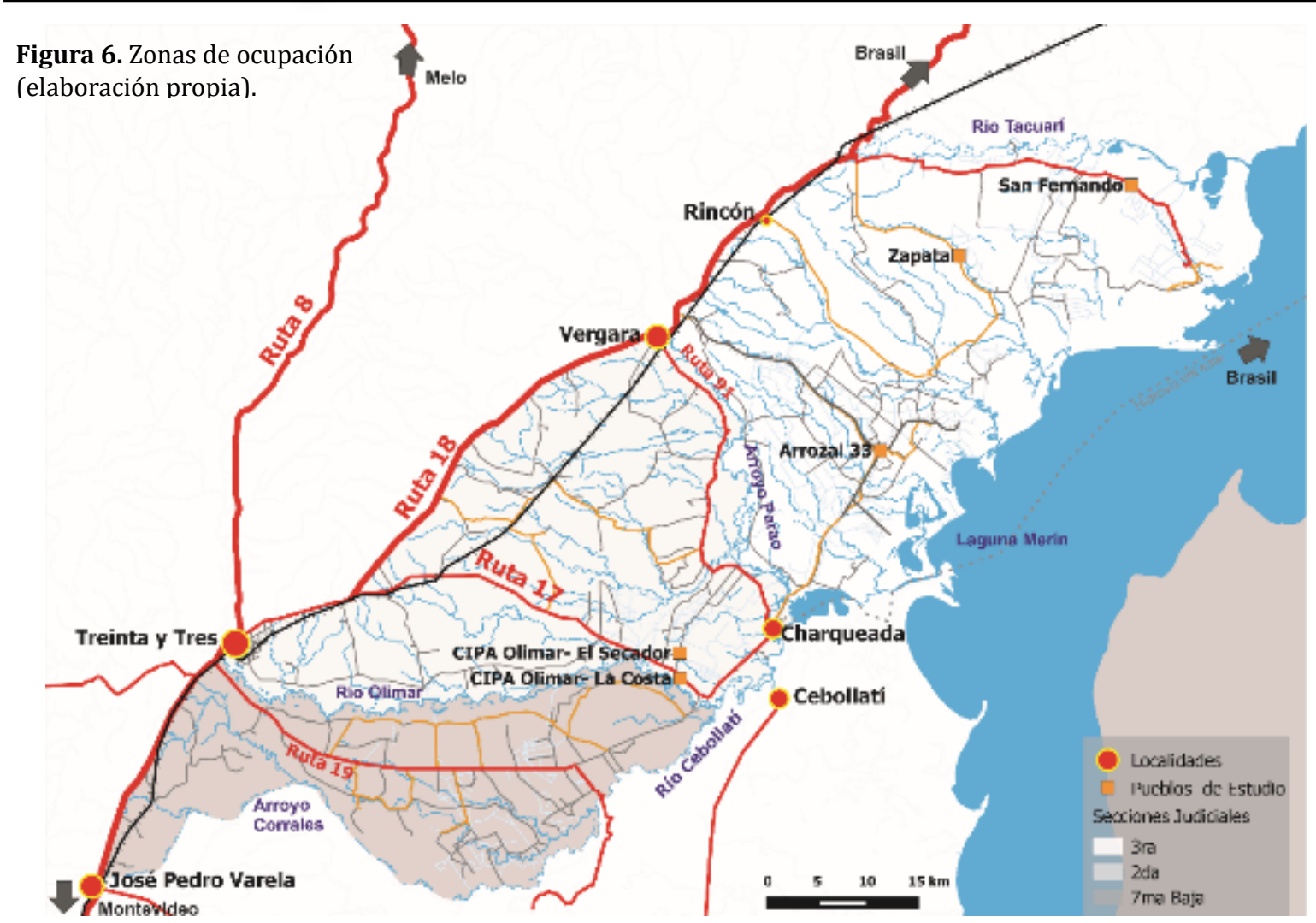

Las instalaciones y las edificaciones de los pueblos conforman un sistema, dentro de un sistema mayor que actúa como contexto.

Así, el molino y los silos, sobre todo en los primeros emprendimientos fueron centrales. Su organización consistió en articular diferentes construcciones en un estricto orden funcional. Los nexos internos solamente son constituidos por vías donde predominan las líneas de circulación que siguieron reglas internas, de tal manera que los itinerarios peatonales no se cruzan.

La composición se limita a la ordenación de viviendas y demás edificios dispuestos de acuerdo a una lógica funcional. Se emplean tipologías para las viviendas, ya que el tiempo y la economía en dinero y trabajo se plantean como condicionantes a la hora del planeamiento. Estas tipologías no son las mismas en todos los emprendimientos, cada cual reproduce la suya propia. Para los silos y galpones se usaron elementos tipos, cuya decisión se explica por la reducción de proyectos y construcción de la obra.

Si bien no se encontraron demasiadas fuentes documentales del proceso de construcción de los asentamientos, se localizaron algunos planos del conjunto de los edificios que constituyeron la documentación de referencia al momento de construcción, asimismo fotografías, algunas de uso empresarial y otras tomadas por técnicos y trabajadores.

Ese legado con las construcciones e instalaciones, caminería, canales de riego, represas y obras de regadío, conforman un conjunto y un sistema dentro del sistema de pueblos de la región.

\subsubsection{Viviendas}

Se desarrollan a través de tipologías: hay viviendas unifamiliares individuales, apareadas o agrupadas y viviendas colectivas de tipología lineal con baños comunes.

Las construcciones están asociadas a su finalidad estrictamente funcional, para ellos se emplean los recursos disponibles. Se recurre a la repetición de elementos con materiales del lugar, fácil disponibilidad y bajo costo. Las construcciones son estándar, basadas en la tipología como principal herramienta de diseño en la implantación del sistema. 


\section{Labor \& Engenho}
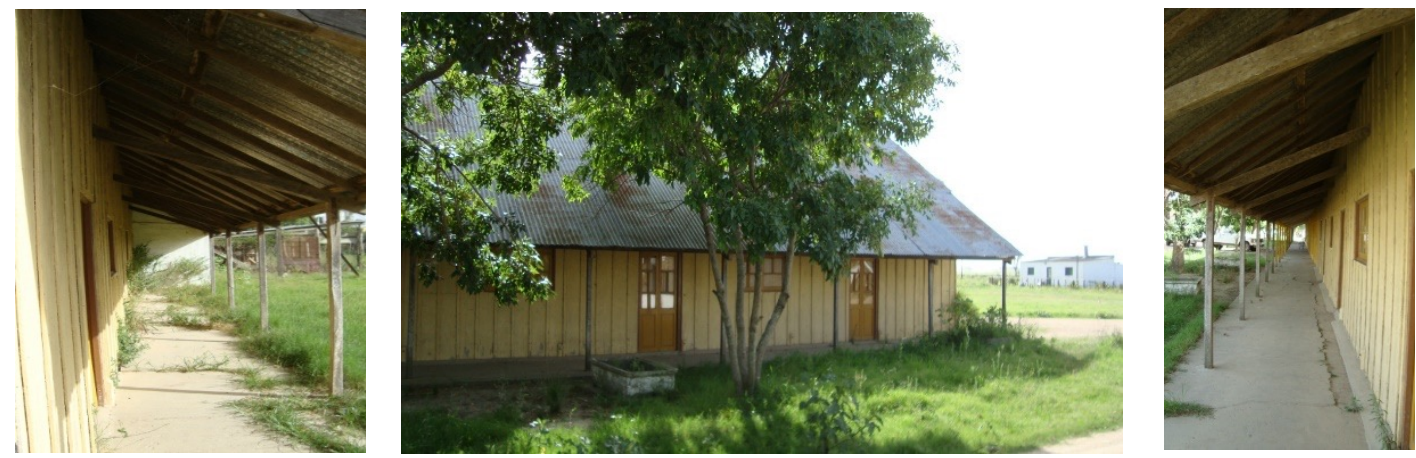

Figura 7. Pabellones para solteros en Arrozal 33. Fuente: S. Martínez.

Con una larga tradición en construcciones de barro en el medio rural, las primeras viviendas para los trabajadores de los pueblos del arroz se resuelven de fajina y adobe con techo de paja ${ }^{5}$. El sistema admite la prefabricación de paneles modulares autoportantes, que uniéndose entre sí, permiten armar muros ciegos o con aberturas. Por su escaso peso y dificultad de armado, pueden ser fabricados, manipulados y montados por dos personas sin necesidad de maquinaria alguna. Consiste en una estructura de madera que recibe una trama de cañas o listones, a la cual se aplica un relleno de barro estabilizado en estado plástico.
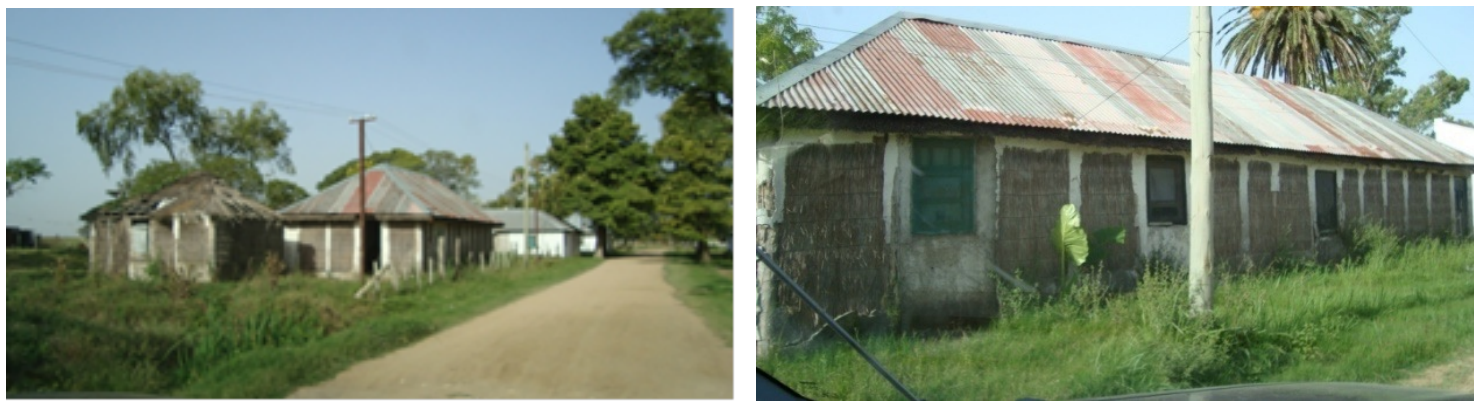

Figura 8. Viviendas de fajina en Arrozal 33. Fuente: S. Martínez.

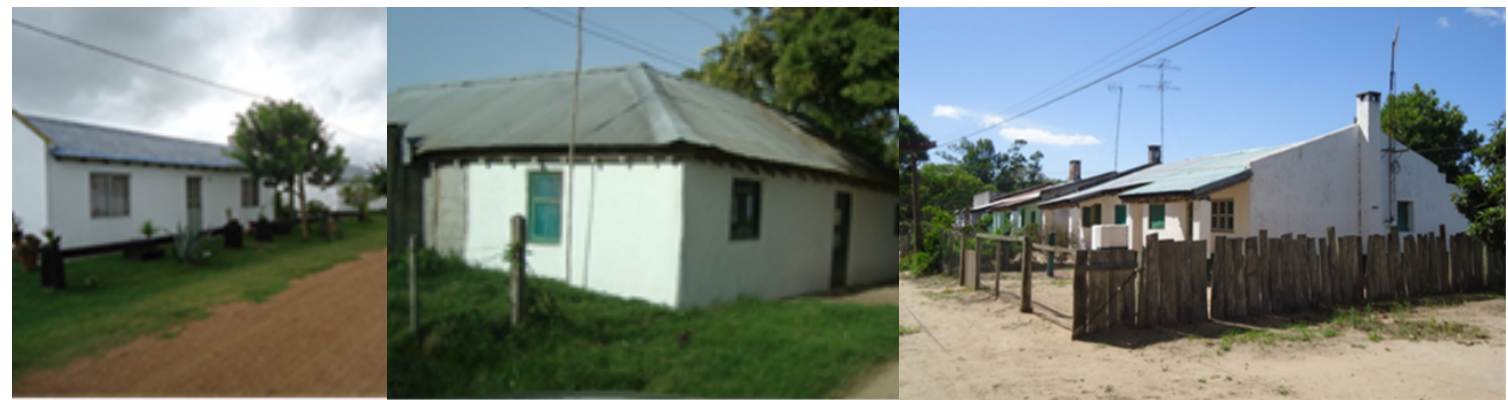

Figura 9. Tipologias de vivienda, San Fernando, Arrozal 33 y CIPA Olimar. Fuente: S. Martínez.

Al deteriorarse y pensar en su sustitución, en las paredes, se emplean materiales más duraderos como bloque de hormigón, ladrillos o ticholos y en la cubierta superior, techo de dolmenit o chapa con cielorraso de paja, un recurso disponible en la zona de bañados.

\subsubsection{Secador}

Las instalaciones del secador componen un conjunto de construcciones que permiten el secado del arroz: una tolva para descarga del cereal de la chacra donde comienza el proceso de secado, un transportador helicoidal, ( $\sin$ fin) que vierte el cereal en la parte superior de la torre de secado que lo recibe con una inyección de aire caliente proveniente de un horno de combustión a leña , otro transportador que traslada el arroz depositado por gravedad en el piso de la torre al silo de enfriamiento y posteriormente al silo de almacenamiento.

\footnotetext{
${ }^{5}$ La fajina es una técnica constructiva artesanal basada en la utilización de materiales naturales, varas de madera y paja.
} 


\subsubsection{Silos}

Utilizados para el acopio de arroz, se construyeron de acuerdo a una tipología funcional, totalmente prefabricados en chapa.
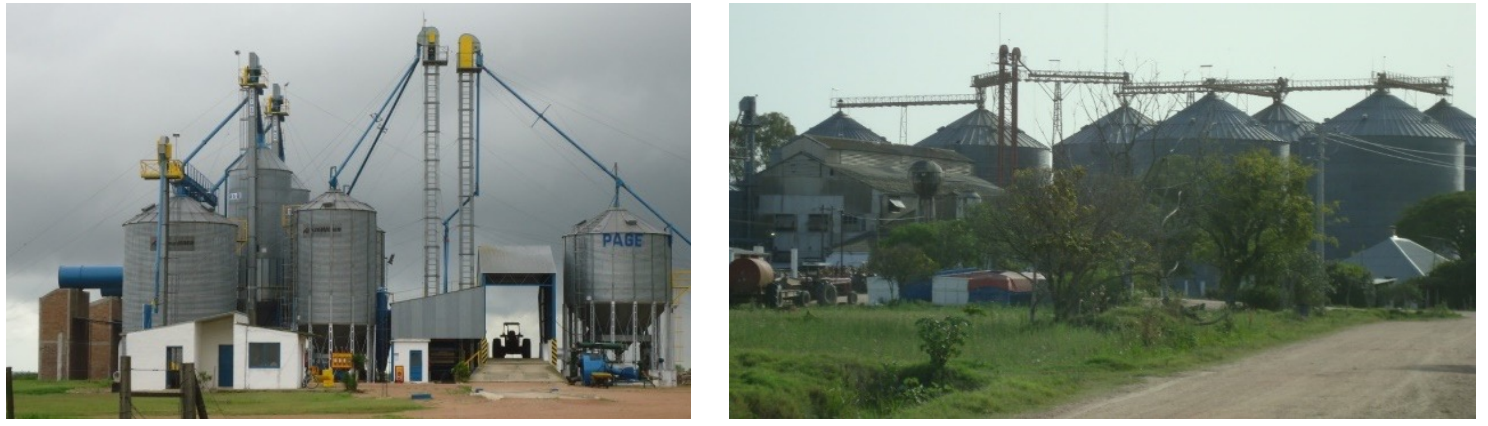

Figura 10. Secador y Silos en San Fernando y La Planta en Arrozal 33. Fuente: S. Martínez.

\subsubsection{Depósito y talleres de maquinaria liviana y pesada}

Usados para almacenamiento y/o reparación de la maquinaria. Las medidas variaron en función de las necesidades. Son construidos en mampostería de ladrillo con cubierta de chapa o totalmente prefabricados en chapa.

\subsubsection{Administración}

Construida en mampostería, generalmente con techo de chapa, En ocasiones se habilita un local dentro del depósito o taller de maquinaria que cumpla estos fines.
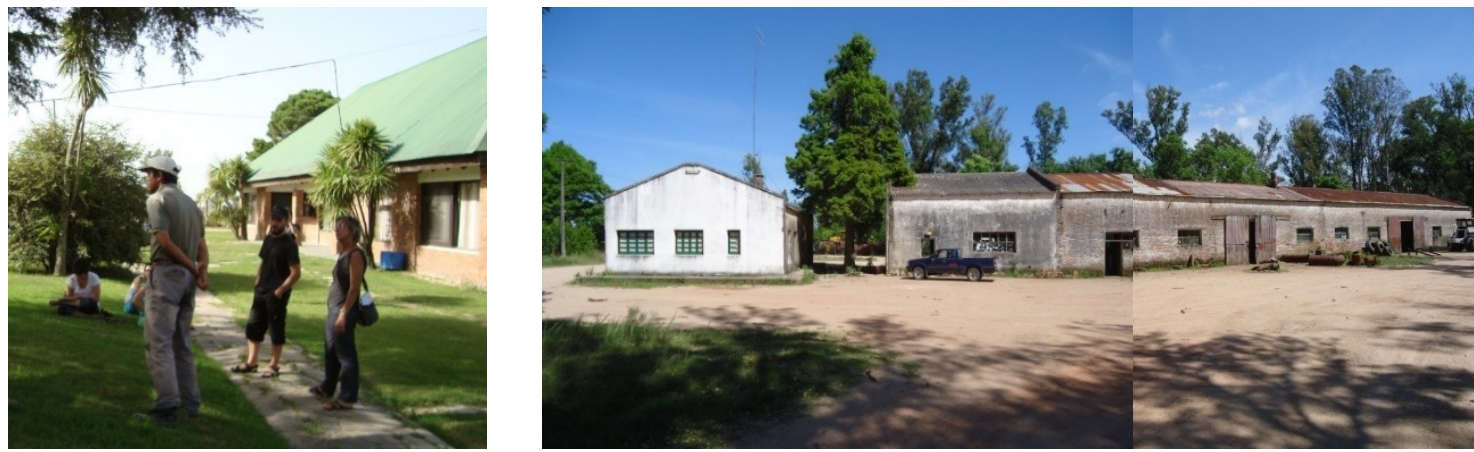

Figura 11. Administración en Arrozal 33, Administración y talleres en CIPA Olimar. Fuente: S. Martínez.

\subsubsection{Servicios de Salud}

Como en general, los servicios de policlínica no son permanentes, se adecúa un local para ese propósito, en la escuela, contiguo a la administración o en alguna vivienda polifuncional.

\subsubsection{Escuela}

Para el edificio escolar, se adaptan construcciones existentes o se resuelven muy austeramente, las instalaciones para albergar a los niños de la zona y la vivienda habitación de la maestra.

\subsubsection{Iglesia}

No se encuentran en todos los pueblos, pero en los primeros, como CIPA y Arrozal 33 formaron parte del conjunto de edificios. Los curas párrocos de las localidades cercanas concurrían semanalmente a oficiar misa.
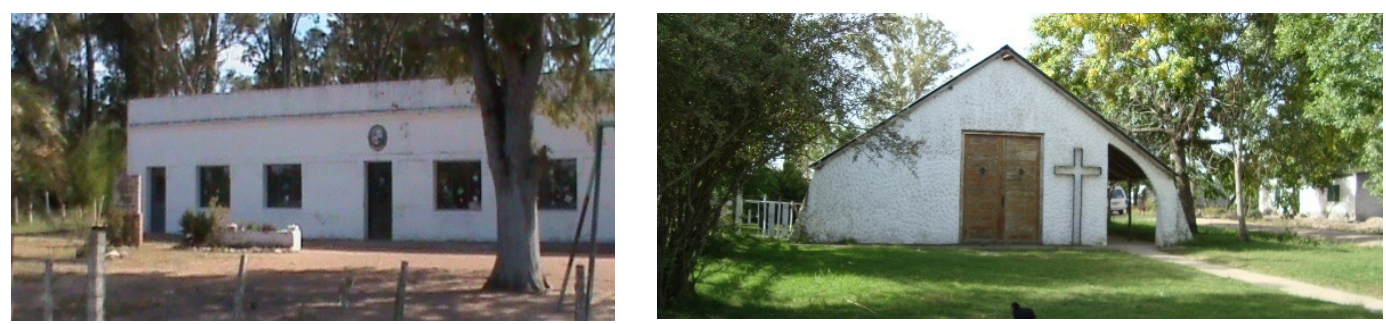

Figura 12. Escuela en CIPA Olimar e Iglesia en Arrozal 33. Fuente: S. Martínez. 


\section{Caso de Estudio}

\subsection{Arrozal 33}

Arrozal "33" S.A. es una empresa agroindustrial fundada en 1934. Su actividad se centra en el cultivo, industrialización y exportación de arroz. Explota una superficie de aproximadamente 8.500 ha anuales dedicadas al cultivo, a las que se suman 1000 ha de productores.

\subsubsection{Análisis morfológico}

Los elementos determinantes de la ubicación y del trazado de Arrozal se relacionan con su ubicación relativa dentro del área de cultivo, la cercanía a la fuente de extracción de agua para el riego y la construcción del último tramo de vía férrea que conectaba Montevideo con Río Branco.

El secador se sitúa al borde la vía férrea, a escasos metros de la R18 y de Vergara. La Central, el pueblo, se localiza a $26 \mathrm{~km}$ por un camino, que corre paralelo al emplazamiento de la antigua línea interna de ferrocarril, a escasos km de la Laguna Merim y el arroyo Ayala. Presenta un contorno irregular en una trama mayor radial, que surge a partir del núcleo central, apoyada en una red de caminos internos que se extienden hasta el área productiva.

Los elementos determinantes en la traza son las centralidades y jerarquías. El pueblo surge en torno las instalaciones industriales, y se desarrolla sobre los accesos que conectan estratégicamente el pueblo con el área de cultivo y las obras para el manejo del agua de riego provocando una trama lineal y dispersa al borde de las vías principales (Figura 13).
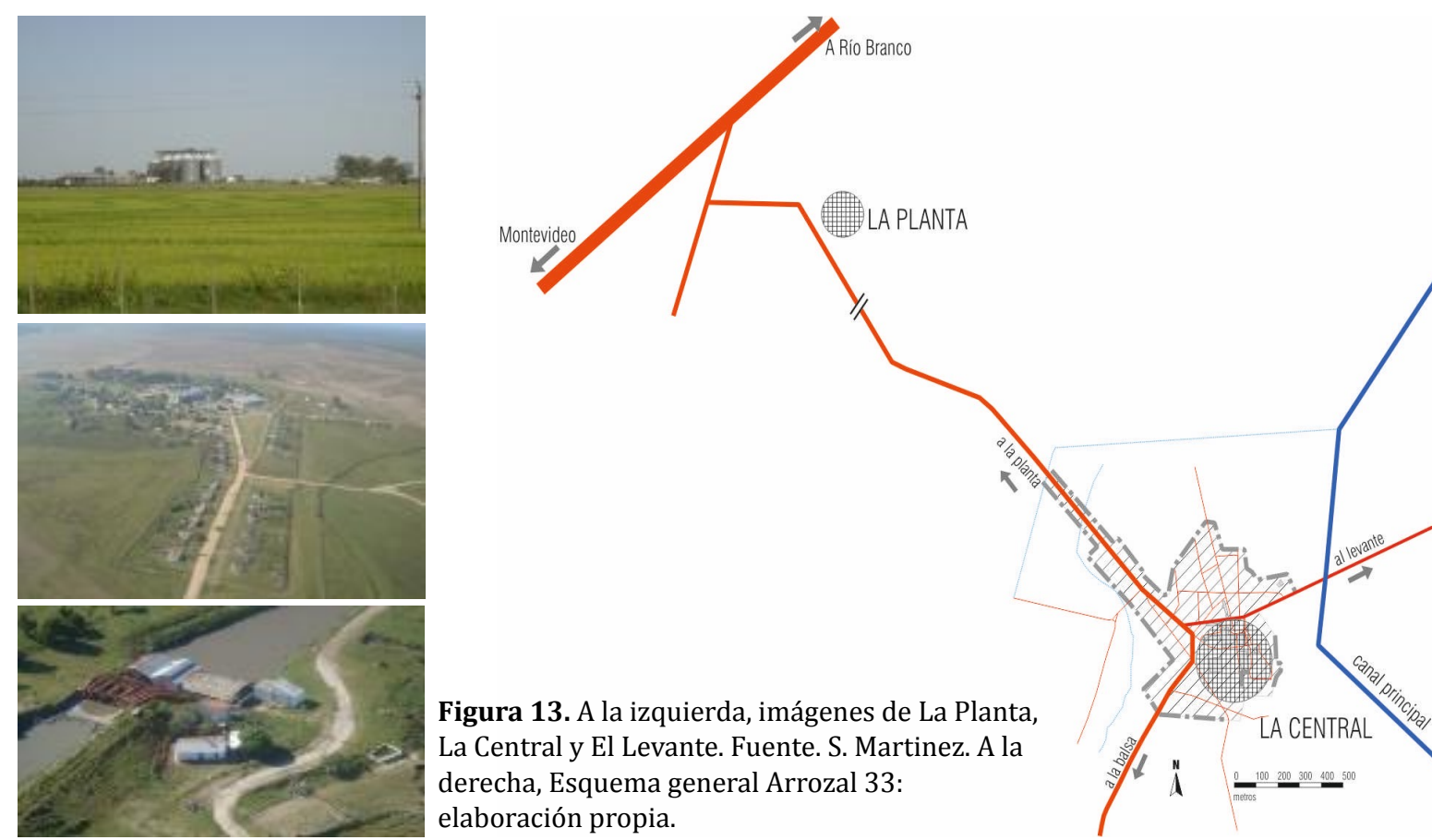

Los componentes del trazado son: las vías de conexión, principales; Camino al Ayala o a la Balsa, $\mathrm{Al}$ Levante o La Guacha a La Planta o Vergara, y secundarias; a los campos de cultivo y los internos en la central y en el sector de viviendas obreras, los canales de riego y los edificios; instalaciones industriales y de apoyo a la producción, viviendas obreras, de técnicos y personal calificado, edificios de uso colectivo; escuela, iglesia, almacenes, club social y el espacio común para actividades de esparcimiento y recreación.

El trazado delimita claramente el uso del suelo, y define las funciones espaciales establecidas y asimismo el carácter y la dimensión de las funciones territoriales instituídas (Figuras 13 y 14). 


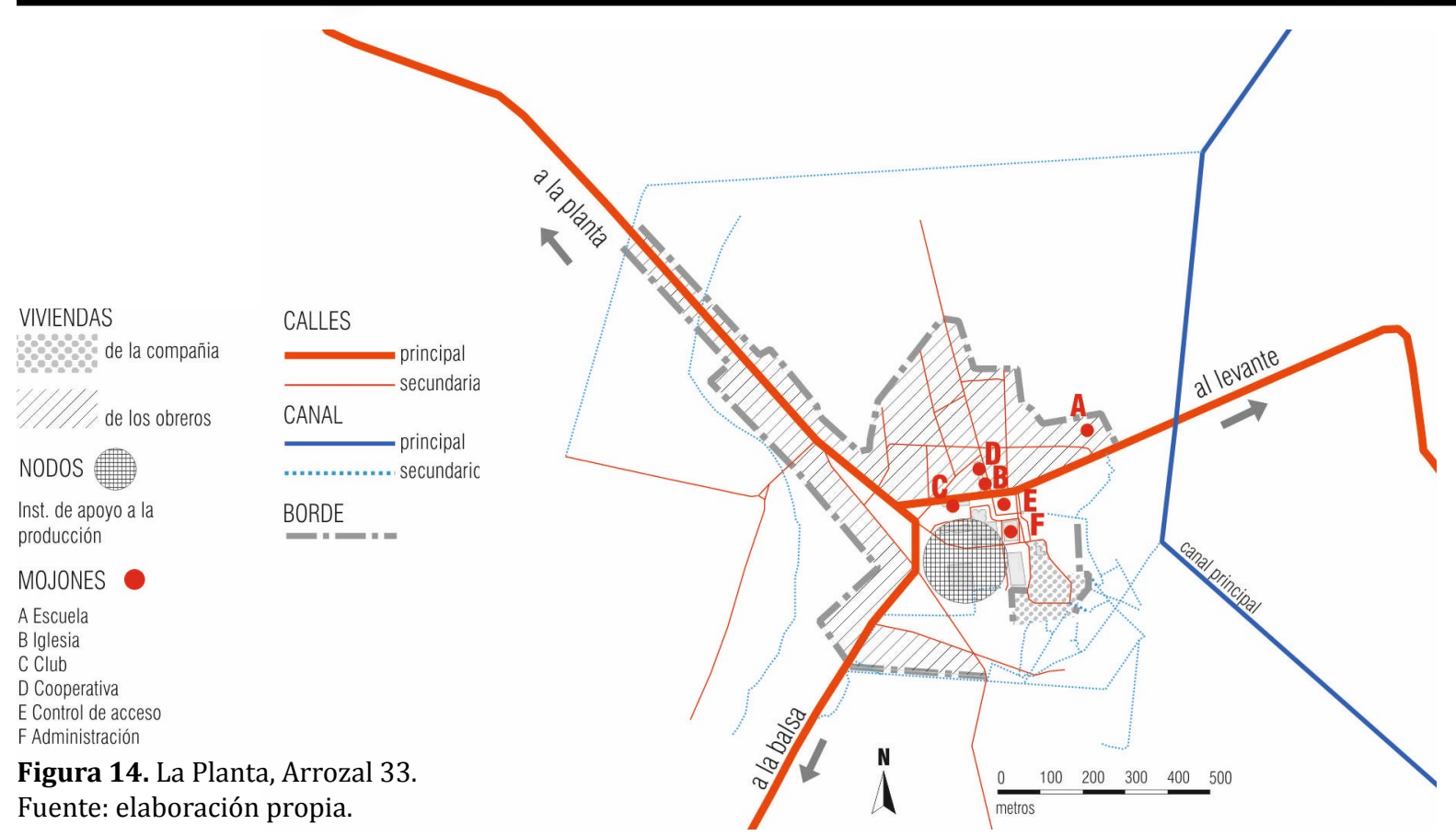

\subsection{Arrozal San Fernando}

Propiedad de "Casarone Agroindustrial", desarrolla actividades industriales en el sector arrocero desde la década del 50 y además en forma directa actividades agrícolas y ganaderas. Es una sociedad del sector arrocero con larga trayectoria en la región, integrada verticalmente. Sus actividades involucran todas las etapas de la cadena productiva, desde el cultivo de arroz en chacra hasta la exportación del producto terminado. San Fernando explota un área de 1.900 hectáreas en la zona y aproximadamente 20.000 en todo el país.

\subsubsection{Análisis morfológico}

Se emplaza a $32 \mathrm{~km}$ de la R18 por el camino Costas del Tacuarí a $2 \mathrm{~km}$ de distancia de la toma de agua principal para el riego del grano, sobre el Río del mismo nombre. El establecimiento agrícolaganadero se compone de tres nodos vinculados entre sí: las instalaciones para el desarrollo de las actividades ganaderas, las instalaciones industriales y el pueblo donde viven la mayoría de los trabajadores de la empresa, localizados a ambos lados del camino de principal. El emprendimiento presenta un desarrollo lineal, se relaciona con el camino, que oficia de estructurador entre los distintos nodos.

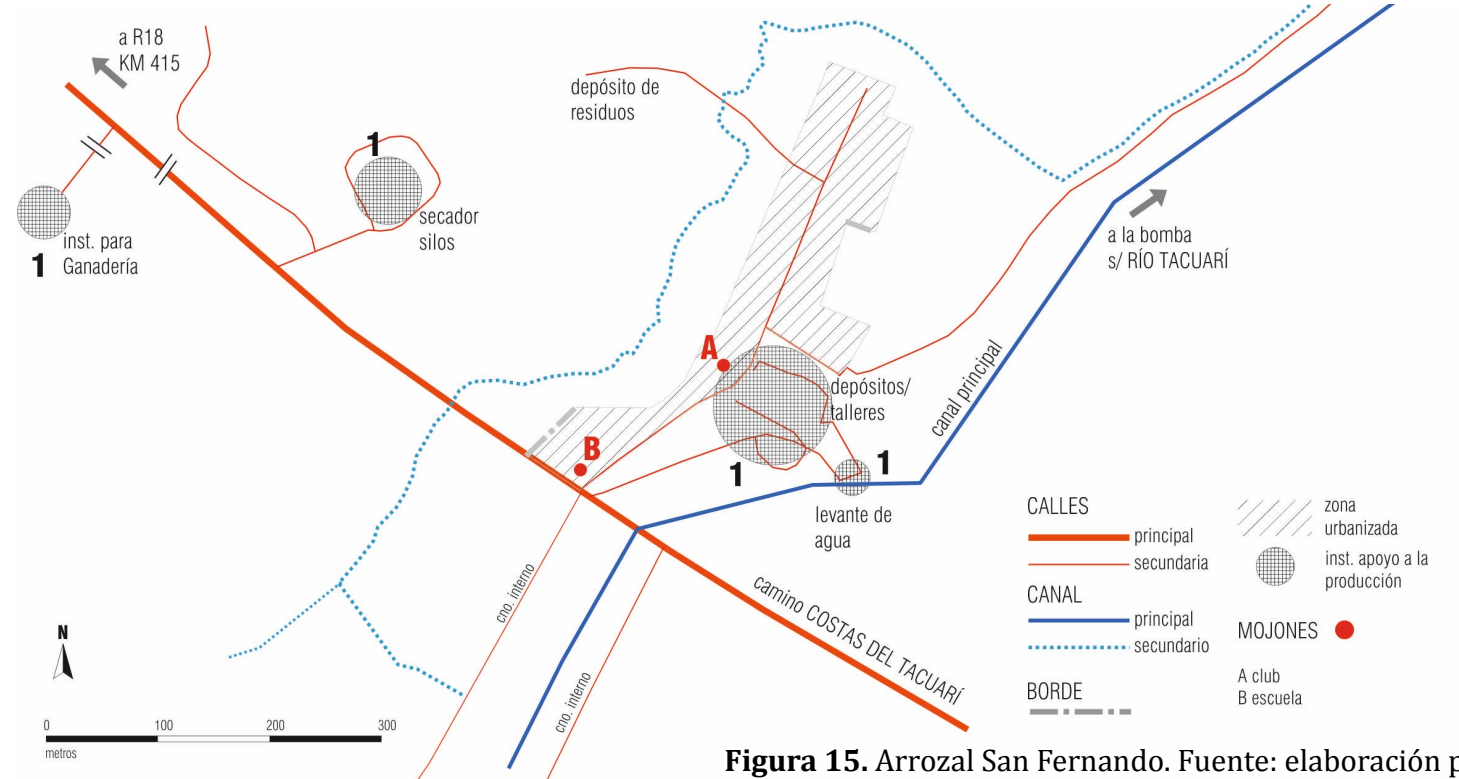

Figura 15. Arrozal San Fernando. Fuente: elaboración propia. 
El poblado se extiende al norte de la arteria de ingreso al área. Se accede e inmediatamente se produce una bifurcación donde una de las vías conduce al pueblo y otra al sector de mantenimiento y logística, a las instalaciones del levante de agua y a la toma sobre el río Tacuarí.

Sobre la vía principal se localiza la escuela y se distribuyen a ambos lados las viviendas obreras, el edificio de administración y del personal técnico, el club y la plaza. Y conforme a ella se organizan y conectan los elementos constitutivos del asentamiento. El arbolado de la calle de acceso al pueblo refuerza la importancia de la senda brindando continuidad espacial a lo largo de su desarrollo.

No se aprecia amanzanamiento alguno, los predios se distribuyen a ambos lados de la calle central en parcelas generosas conformando un tejido abierto y disperso, con una textura de grano grueso, ya que los elementos constitutivos son diversos y con diferente relación entre ellos.

La red de caminos internos se distribuyen en diversas direcciones hacia los campos de cultivo, que se extienden a ambas márgenes del camino principal.
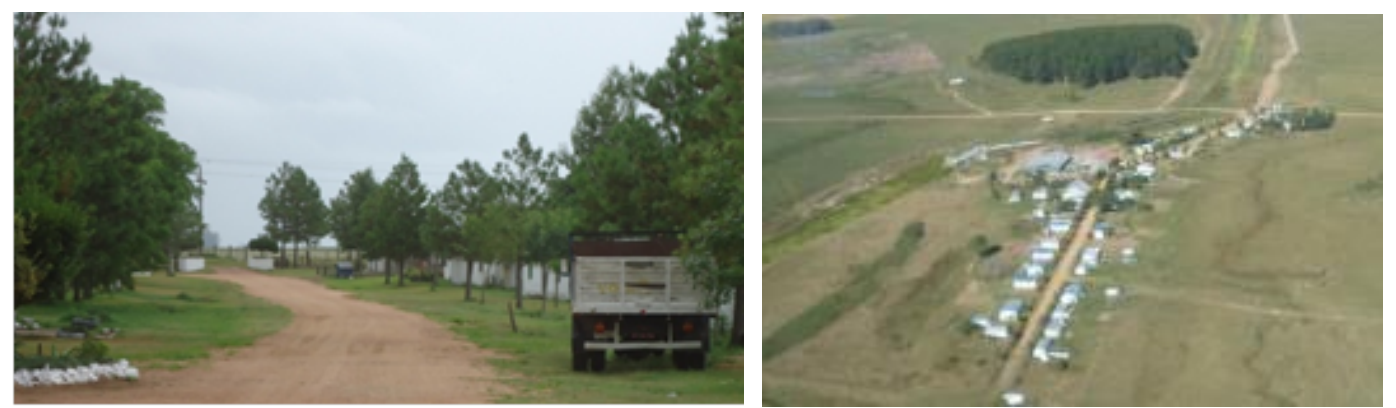

Figura 16. A la izquierda, la calle principal; a la derecha, "parcelas generosas conformando un tecido abierto y disperso". Fuente: S. Martinez.

\subsection{Arrozal Zapata}

Propiedad de Raab Hnos, Zapata; es una de las más grandes empresas arrocera de la zona, ubicada en la costa del arroyo homónimo. Explota una superficie de 2.500 hectáreas para el cultivo entre propias y arrendadas. En el pueblo viven alrededor de 100 personas que en época de zafra llegan a triplicarse.

\subsubsection{Análisis morfológico}

Se accede por un camino vecinal “Camino a Zapata." Se localiza a 30 km de la localidad de Rincón, a 19 km del empalme de Ruta 18 con el Camino Costas del Tacuarí muy cercana a la toma de agua para riego; el Arroyo Zapata y la Laguna Merim.

El pueblo se desarrolla en forma lineal a lo largo del camino principal. Su disposición revela un contorno bastante regular limitado por los canales de riego y los campos productivos.

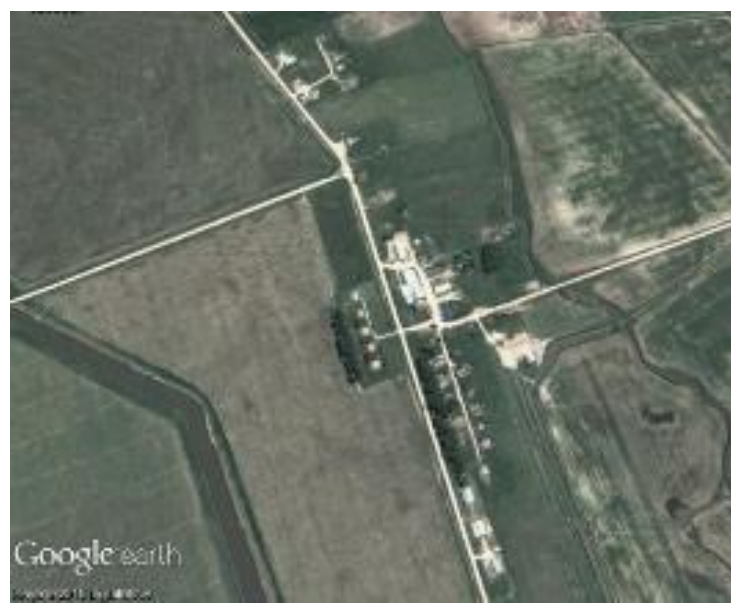

Sin saberlo, sigue el modelo de Arturo Soria y Matta, formulado a fines del siglo XIX, que propone una ciudad lineal construida contigua a una avenida, con un corredor central de infraestructuras y en sus márgenes bosques para aislar de los campos de cultivo. Muchas veces, sin planeamiento explícito se han adoptado a lo largo de la historia esta forma lineal, para el desarrollo o el crecimiento de centros poblados, creciendo en ambas márgenes de algún camino, río o canal.

Figura 17. Arrozal Zapata. Fuente: Google Earth, 2015.

(C) Labor \& Engenho, Campinas [SP] Brasil, v.10, n.3, p.283-301, jul./set. 2016. 


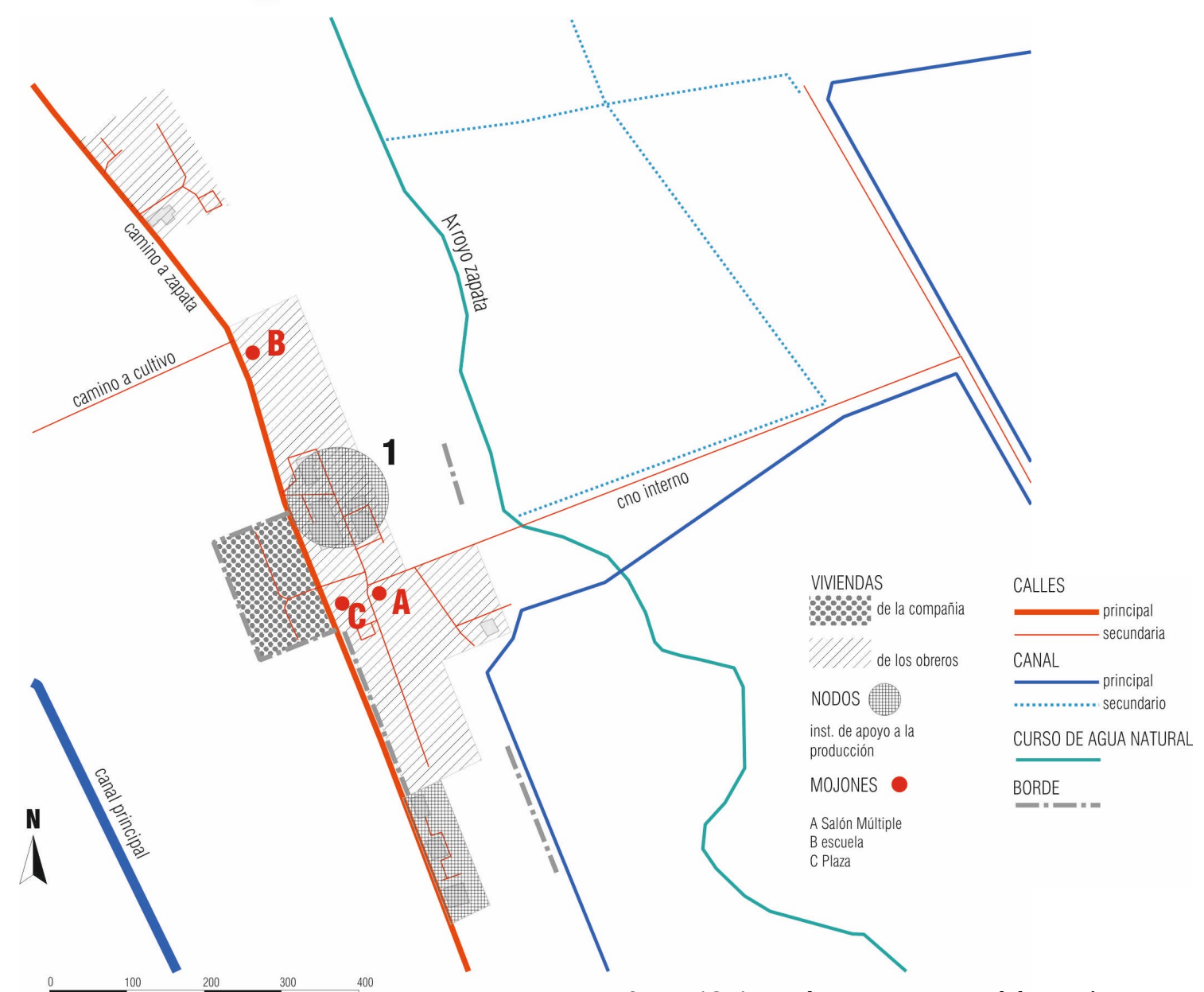

Figura 18. Arrozal Zapata. Fuente: elaboración propia.

El elemento más importante es el trazado de la red vial. En Arrozal Zapata, la vía principal es el camino. Se consolida además, una calle de circulación paralela que se conecta a la primera en los puntos medulares.

Los campos de cultivo se despliegan en torno al pueblo donde los canales de riego se prolongan como arterias, constituyendo los bordes o límite entre las dos fases. Los caminos que conectan con el área productiva, se disponen en forma perpendicular al principal conformando una red interna que permite el desplazamiento de personas y maquinarias.

Se constata la existencia de un nodo, donde se ubican los edificios destinados a administración, servicios y a actividades comunes.

En el sector este, se materializa la mayor parte del pueblo. Se desarrollan de sur a norte depósitos y talleres sobre la vía principal, viviendas de los trabajadores aisladas del camino central por una hilera de árboles, a continuación, el sector administrativo, servicios y de apoyo a la producción finalizando en el extremo norte con otro sector de vivienda de trabajadores.

En el sector oeste, en el centro del pueblo, se sitúan en hilera, las viviendas de los propietarios edificadas can características similares.

El uso del suelo urbano, está delimitado físicamente por calles, bosques, canales y campos de cultivo.

El espacio de uso colectivo para esparcimiento, se encuentra en la entrada principal a ambos lados de la calle de penetración, enfrente a las viviendas de los dueños, constituyéndose conjuntamente con el salón de reuniones en el mojón del pueblo. 


\subsection{CIPA Olimar}

Desde la creación en 1928 por un grupo de ingenieros y empresarios uruguayos, se desarrolló la actividad agrícola ganadera en una extensión de 9000 has de campo, donde se siembran aproximadamente 2000 hás anuales de arroz. En el año 2002, la tierra pasa a ser propiedad de extranjeros. Actualmente la producción está a cargo de una multinacional que trabaja con productores uruguayos.

\subsubsection{Análisis morfológico}

La ubicación y el trazado de CIPA Olimar, como en la generalidad de las situaciones está ligado a la extracción del agua para riego, las tierras de cultivo y la accesibilidad desde los centros principales. Se ubica a 50 km de la ciudad de Treinta y tres, por R17 y a 12 km de José E. Martínez (La Charqueada).

El pueblo se desarrolla en dos polos, uno directamente vinculado al río, el "Pueblo de la Costa" y el otro a las tierras de cultivo el "Pueblo del Secador".

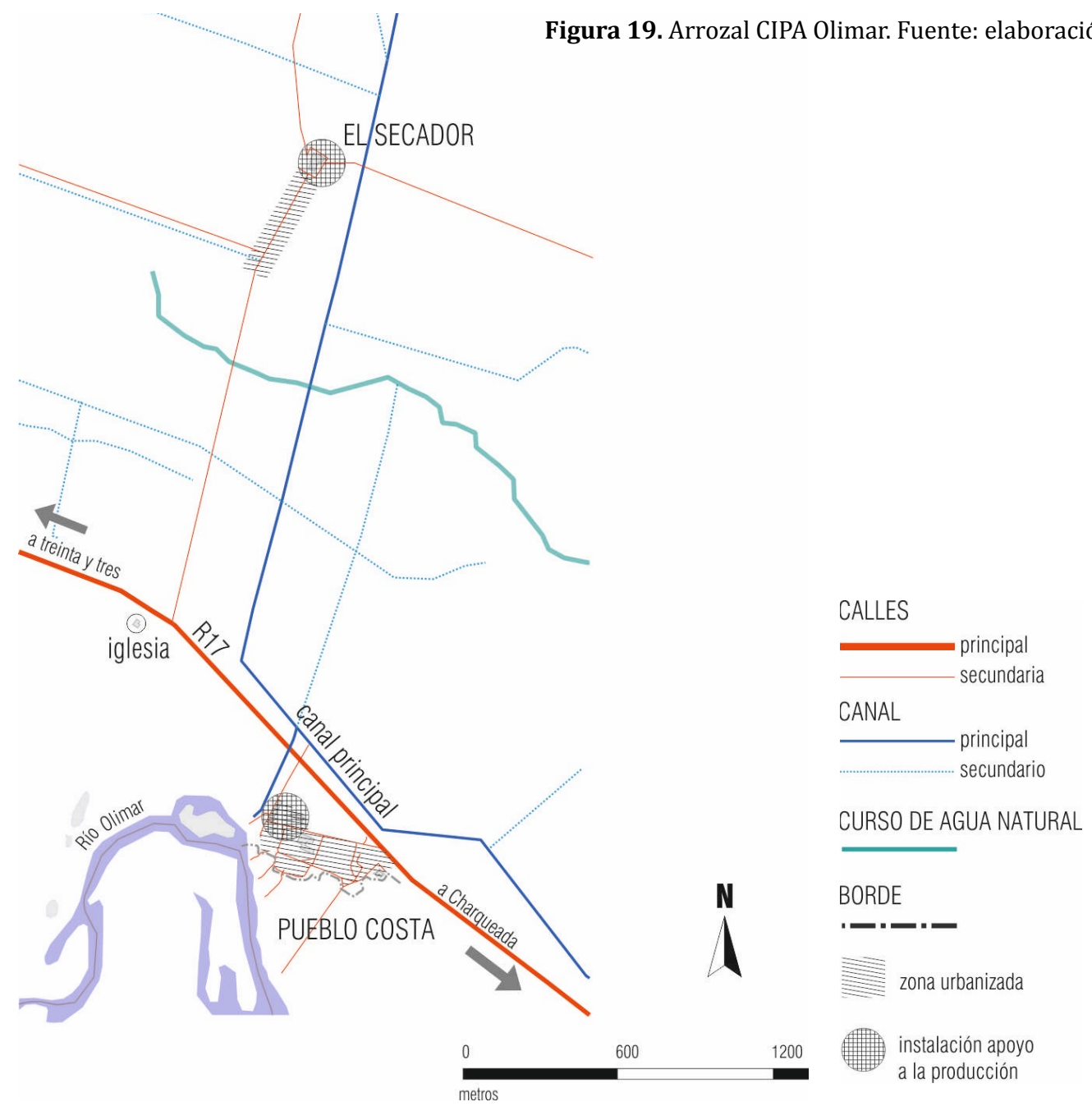

La Iglesia se ubica en una situación peculiar, en la margen sur del cruce de la R17 con el acceso al Pueblo del Secador, equidistante de los dos centros o barrios que conforman las instalaciones de CIPA Olimar. Se constituye en un mojón ${ }^{6}$, al ser un elemento aislado, ubicado en la convergencia de sendas de acceso a ambos polos. Y es en ese punto, centro de reunión semanal de la comarca, equidistante de los pueblos, donde se cambia de dirección. Tanto para los habitantes del Pueblo de la Costa como para

\footnotetext{
${ }^{6}$ Para K. Lynch (1960) los mojones son puntos de referencia, objetos físicos sencillos, cuyo uso implica la selección de un elemento entre otras posibilidades. LYNCH Kevin . 1960. "The image of the city" Massachussetts Institute of Technology Press, Cambridge (Massachussetts), 1960 “La imagen de la ciudad”. Editorial GG, Barcelona. 1984-1998,Pp 61-102.
} 
los del Pueblo del Secador, la iglesia, al ubicarse estratégicamente en la confluencia de ambas sendas, adquiere especial importancia simbólica, ya que se destaca por su singularidad en un contexto vacío de construcciones transformándose en un elemento significativo que contrasta con el paisaje de fondo.

\subsubsection{Pueblo del Secador}

Se accede desde la Ruta Nacional 17, en el km 335,5 al norte. Se desarrolla en forma lineal a aproximadamente $1500 \mathrm{~m}$ de la entrada.

El pueblo se concibe en torno a un eje vial de orientación norte-sur paralelo al canal principal de riego conformando un paisaje de extraordinaria fuerza organizadora. Sobre esta camino, se disponían a ambos márgenes los pabellones de solteros, viviendas de trabajadores, el conjunto de baños públicos, así como los edificios de equipamiento, escritorio, club social, policlínica, comisaría, carnicería, almacén y cocina-comedor colectiva para el personal obrero.

La calle principal remata en una playa de estacionamiento al servicio de las instalaciones industriales para el secado y acopio del grano y las complementarias como galpones y balanza. Desde esta calle, la principal del pueblo, parten las sendas hacia los campos de cultivo alternando en su estructura con los canales de riego.

El camino y el cauce de riego constituyen los elementos canalizadores a través de los cuales se producen los flujos de personas, bienes y servicios para la producción y la conducción del agua a las áreas de explotación agrícola.

Este asentamiento fue desvastado por el actual propietario de la tierra, luego de la crisis financiera que soportó el país en el año 2002 y el establecimiento pasó a manos extranjeras, Permanece activo solamente el Secador, los silos y la balanza?.
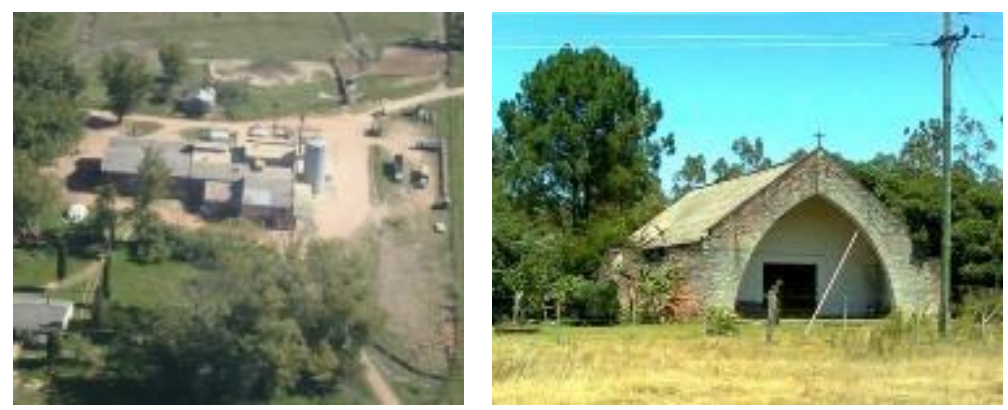

Figura 20. A la izquierda, el Secador; a la derecha, la Iglesia La Costa.

Fuente: Susana Martinez.

\subsubsection{Pueblo de la Costa}

Al Pueblo de la Costa se ingresa en el $\mathrm{km} \mathrm{336,3} \mathrm{de} \mathrm{la} \mathrm{ruta} \mathrm{17,} \mathrm{por} \mathrm{dos} \mathrm{vías} \mathrm{de} \mathrm{acceso} \mathrm{principales}$ separadas 400 metros entre sí. El pueblo se circunscribe dentro de límites topográficos, determinando el uso del suelo urbano. Se desarrolla entre el monte ribereño y R17 limitado en un extremo por un canal mayor que conduce el agua de riego de la toma hacia la zona de regadío y en el otro por un borde más difuso con predominio de vacío sobre lleno.

Se define, en ese contorno, con escasa visibilidad desde la ruta nacional, una trama reticular donde predominan las líneas rectas en el trazado de calles, que se cortan perpendicularmente formando una cuadrícula irregular, dando una gran sensación de orden. El entramado viario, está condicionado por el medio natural y a su vez condiciona la disposición de la edificación y el sistema de movimientos.

\footnotetext{
${ }^{7}$ Las tierras que pertenecieron a CIPA Olimar fueron comprados a posteriori de la crisis del año 2002 por el empresario brasilero Correa, continuando el cultivo del arroz a régimen de medianería por productores de PROCIPA. Siguiendo lineamientos del actual propietario de la tierra, fueron desmanteladas la mayoría de las construcciones del Pueblo del Secador, mientras que las del Pueblo de la Costa se mantienen habitadas por productores y empleados arroceros.
} 


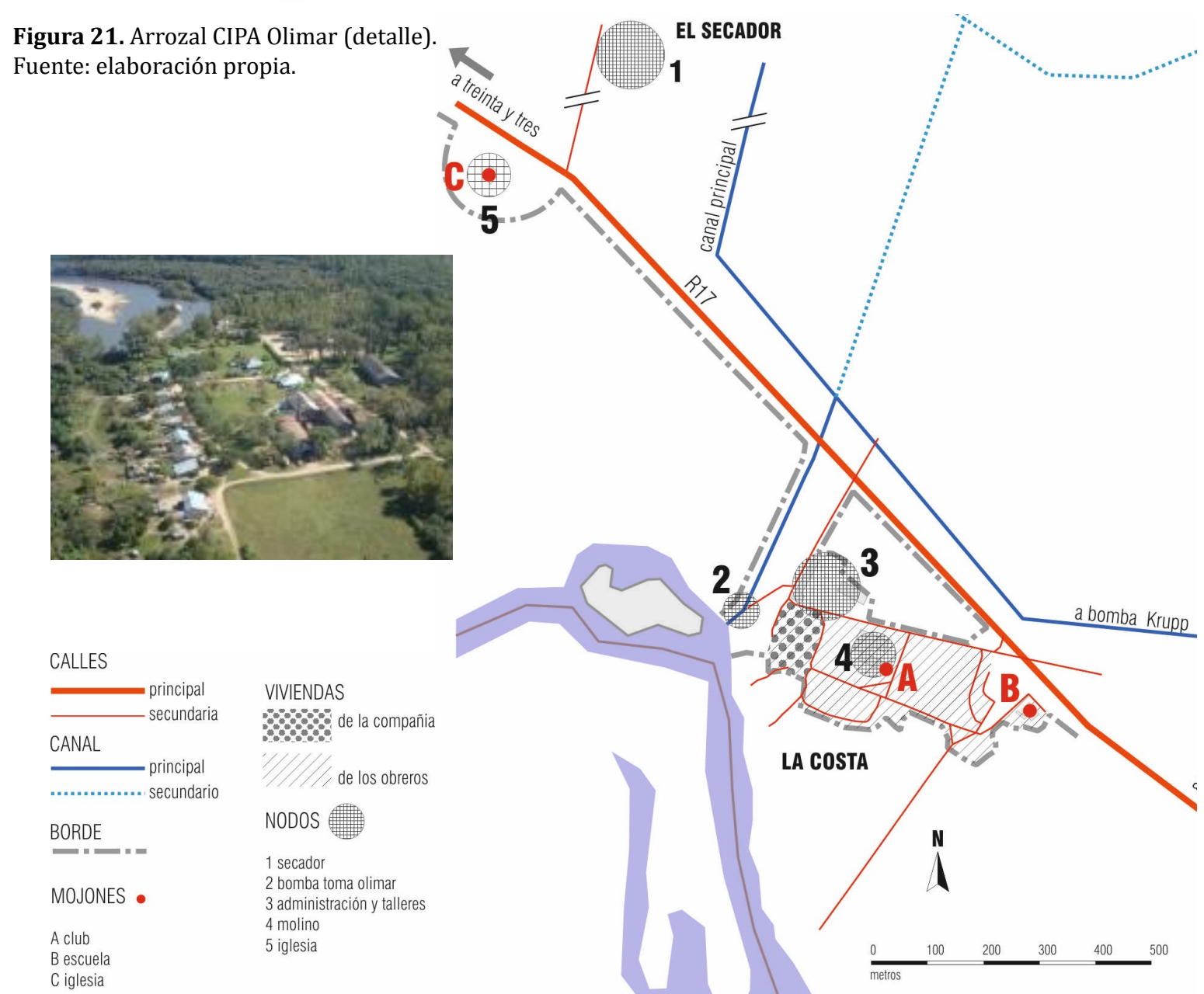

La edificación, la forma y disposición de los edificios responden al uso de las actividades que aloja. Sobre el primer acceso, desde el oeste, en la manzana triangular se extienden edificios administrativos y de servicio, talleres de mantenimiento de maquinaria pesada, liviana, tornería, depósitos y repuestos.

En la primera manzana rectangular se disponen viviendas del personal técnico y gerencial, en la manzana central se ubican el molino, depósitos de arroz y carpintería, además el edificio del club con un espacio libre - plaza- para la interacción social y la gran manzana fue reservada para actividades deportivas al aire libre - la cancha de futbol.

Otras viviendas se distribuyen linealmente en parcelas unifamiliares con fondo al monte ribereño sobre la calle sur con dirección este-oeste, donde predomina el uso residencial que alterna con algún comercio de abastecimiento básico que remata en el edificio escolar ubicado sobre R17.

\subsection{Síntesis y reflexiones}

La instalación del cultivo de arroz, provoca cambios en el paisaje rural incorporando la dimensión urbana y territorial del paisaje antropizado, el paisaje construído.

Se ocuparon nuevos territorios y la instauración de la agricultura constituye una de las primeras huellas del hombre en el paisaje natural.

Los primeros habitantes de estos asentamientos son pobladores de localidades cercanas, como Treinta y tres, Vergara, Rincón, Río Branco, Yaguarón,Charqueada, Cebollatí entre otras, técnicos especializados y los propietarios de las empresas agropecuarias.

Se puede señalar a modo de síntesis los siguientes componentes del sistema de asentamientos de los pueblo del arroz: 
- Surge una nueva forma de ocupación del territorio, en un sistema de red a modo de constelaciones relacionados con los nodos cercanos.

- La estructuración, como en la mayoría de los casos, es funcional, se localizan en el centro de los campos de cultivo o al borde de la red de caminos de acceso.

- La estrategia de localización se vincula con el manejo de los campos de cultivo y la extracción del agua para riego.

- El resultado morfológico de ocupación se relaciona con la caminería, la accesibilidad, que dio como resultado concepción del poblados lineales.

- La trama urbana queda subordinada al camino y a los canales de agua.

- Las obras de infraestructura, para riego, los caminos, los campos de cultivo, el ferrocarril, y los pueblos arroceros se constituyen en los elementos estructurantes del área.

- La debilidad del modelo de desarrollo radica en la dependencia del sistema con la inversión privada, obteniendo como resultado un circunstancial arraigo.

Fueron decreciendo en cantidad de habitantes. Muchas causas originaron esta situación: la tecnología, la accesibilidad, la educación de los jóvenes y la búsqueda de oportunidades en comunidades mayores.

El sector arrocero, se caracteriza por ser una cadena agroindustrial integrada, que en los últimos años ha demostrado crecimiento en la producción. Uruguay posee una excelente reputación a nivel internacional como productor y exportador del grano.

Si bien el cultivo no tiene un comportamiento expansivo en su superficie, constituye un sector de captación y aplicación de otros recursos productivos: mano de obra, tecnología del cultivo, inversión en instalaciones, transporte y potencialmente, revalorizando los pueblos, y el entorno natural en el cual se inscribe, se pondría en funcionamiento el sistema territorial con un nuevo enfoque a favor del territorio y el desarrollo sostenible.

Conocer este patrimonio nos abre las puertas no solo a la difusión del conocimiento sino a la valoración de legado histórico cultural que marcará la identidad a futuro. Para su preservación y su posible utilización, debe pensarse como una huella, eje del sistema que cambió por completo el orden territorial, testimonio de valores sociales y culturales.

\section{Referencias}

Barrán, J.P. (1995). http://www.rau.edu.uy/uruguay/historia/Uy.hist4.htm (Consulta 3/01/2015).

Comisión Mixta Uruguaya Brasilera para el desarrollo de la Cuenca de la Laguna Merim — [CLM] (s./d.). Consulta a documentación existente en CLM Treinta y Tres, ubicada en Santiago Gadea entre Juan Antonio Lavalleja y Manuel Freire.

Comisión Social Consultiva [COSOCO] (2003). Promoción de políticas microregionales y locales para un turismo ambientalmente sustentable. Las pequeñas localidades y sus microrregiones alternativas de desarrollo. Proyecto Turismo y Patrimonio. Montevideo: Universidad de la República [Facultad de Arquitectura \& Facultad de Ciencias].

Consultores INTECSA-EYSER. Comisión Laguna Merim, Delegación uruguaya (1981, Junio). Estudio de factibilidad del aprovechamiento hídrico para riego e hidroeléctrico del Río Tacuarí (Tomo IIIi, 192 p.). Madrid, Estudios básicos de Ingeniería 3.12 - Zona regable.

Garcés Feliú, E. (1999). Las ciudades del salitre (145 p.). Santiago: Editorial Orígenes.

Garcés Feliú, E. (1997/II). Oficina salitrera Chacabuco Company town en el desierto de Atacama(Chile). Revista Rassegna 70, Santiago, Chile. Versión PDF, en www.memoriachilena.cl

Ferrari, M. (2011). Los asentamientos urbanos producidos por la instalación del ferrocarril en el noroeste argentino. Apuntes 24 (1), 26-43. 
Ferrari, M. (2011). El sistema ferroviario en el noroeste argentino. Arquitectura e instalaciones complementarias. Apuntes 24 (1), 44-61.

Lynch K. (1960). La imagen de la ciudad (pp. 61-102). Barcelona: Editorial GG. 1984-1998.

Maestría de Ordenamiento Territorial y Desarrollo Urbano (2009, Octubre). Cuenca del Cebollatí. Nuestro territorio, ... un proyecto compartido - Formulación de bases de ordenamiento territorial y desarrollo sostenible para la Cuenca del Río Cebollatí (301 p.). Acuerdo MVOTMA-DINOT_IMTyT, IMR, IML_ MOT, FArq-UdelaR.

Ministerio de Transporte y Obras Públicas (2007, Septiembre). Aprovechamiento de los recursos hídricos superficiales Cuenca de la Laguna Merim \& Cuenca del Océano Atlántico (62p.). Montevideo, Uruguay.

Medina, M. (2005). Construir el futuro revalorizando el pasado. El turismo cultural, una alternativa de desarrollo en el territorio metropolitano de Montevideo. Tesis de Maestría de Ordenamiento Territorial y Desarrollo Urbano, Universidad de la República, Montevideo, Uruguay.

Medina, M., Piazza, N., Leich, E., \& Garat, D. (2006). Criterios de manejo del paisaje como recurso turístico en el Uruguay. Montevideo: Universidad de la República. Edición financiada por la Comisión Sectorial Científica de la UdelaR.

Montaner, J.M. (2008). Sistemas arquitectónicos contemporáneos. Barcelona: Ed. GG.

Perez Bustamante, L. (s./d.). La mirada y la memoria. Elementos de estructuracion y revalorizacion del paisaje cultural de Lota Alto. Chile. Microsoft Power Point. http://www.dibam.cl/dinamicas/DocAdjunto_1141.pdf

Perez Bustamante, L. (2009). Los miradores de Lota Alto; lugares de encuentro, comprensión y revalorización del paisaje cultural. Chile (pp.109-122). Revista Conserva 13. http://www.dibam.cl/dinamicas/DocAdjunto_1525.pdf

Plan Director de la Reserva de Biósfera de Bañados del Este [PROBIDES] (2000, Abril). Bañados del Este Año 7 № 17.

Plan Director de la Reserva de Biósfera de Bañados del Este [PROBIDES] (1999). Plan Director Reserva de Biósfera de Bañados del Este/Uruguay. Ruta 9 km 204 — Rocha, Uruguay. probides@adinet.com.uy. MVOTMA-IMR-IMMaldonadoIML-IMTyT-IMCL. Financiado por la UE, PNUD, Global Environment Facility.

Sabaté, J. (ed.) (2008). Proyectar el territorio en tiempos de incertidumbre. Camp de Terragona: proyectos para una nueva configuración territorial. Barcelona: Universidad Politécnica de Catalunya.

Sabaté, J. (2004). Paisajes culturales. El patrimonio como recurso básico para un nuevo modelo de desarrollo (pp. 08-29). Revista Urban № 9. Madrid, Universidad Politécnica de Madrid.

Sabaté, J. (2005, Marzo). Paisajes culturales en Catalunya: un reto al futuro. ESPAIS, revista de la Generalitat de Catalunya. 